\title{
UNDERSTANDING PEACE FORMATION: A SOCIOLOGICAL PERSPECTIVE
}

\author{
Dodik Harnadi \\ Doctoral student of social science program, faculty of social and political science \\ Airlangga University, Surabaya
}

\begin{abstract}
Peace study is now one of the most debated discourses. In the discourse of peace study, the modes of peace which was based on the liberal western values have long gained supremacy. Three generations of peace study occurred from that liberal tradition. Along with the strengthening - and even the romanticizing- of locality, the liberal peace traditions began to be criticized. Post Liberal Peace presented around the searching for the modes of ideal peace by criticizing the liberal peace traditions that based on liberal values. Post liberal peace or, as Richmond conceptualized, peace formation, was the correction of liberal peace generation and the celebration of the strengthening of locality. Unfortunately, there is theoretical gap, as many theories of that post liberal generation can't elaborate sociologically how locality involved in peace process and bound as social norms. To fill the gap, the literature study uses Giddens's structuration to understand how locality becomes the base of peace formation. Based on structuration theory of Giddens, the study found that local actors could act as an agent with capacity to formulate the mode of peace by standing on the local attributes as the ground as well as cultures and social values-norms. In Addition, the local actors had the both reflexive and discursive consciousness in interpreting the purposes of local values conversion as a base of peace formation.
\end{abstract}

Keywords: Agent; Liberal Peace; Local; Peace Formation; Post Liberal Peace; Structuration.

\section{Introduction}

The conflict and peace study has led to the shifting of a top down towards buttom up approach of peace building. This shift occurred because the peace-building model from the top often ignored the real needs of local communities. Locality was the starting point for this shift.

Oliver Richmond was the avant garde theories who promoted this concept of local peace. A peace formation was a peace-building approach conceptualized by Richmond based on the idea of locality. In his research entitled Peace formation and local infrastructure for peace, Richmond asserted that peace formation was a process of peace formulation that focused on the role of critical agents in ending the state formation cycle that was generally global centric (Richmond, 2013).

The word 'local' was a key concept in that peace building. Richmond used the word 'local' to refer to a number of actors or individuals as well as local resources or human resources (Richmond, 2011). Culture in the form of norms and values becomes an important part of it.

Locality itself presupposes the diversity and dynamics of each community's social life with cultural symbols that also vary. The cultural diversity of each community influences its members to construct and negotiate themselves with various challenges faced. This locality is often marginalized by a global centric approach to peace that was designed from the top. 
This wealth of the local is often ignored in the mechanism of peace building which was generally engineered, even forced, from the top (top down), regardless of the locality of culture and the initiation of local actors who actually has more understanding about what they are experiencing. The standards used to determine how peace was built and the direction in which peace-building was aimed, were only oriented to the liberal western values. They were regarded by the both government and international NGOs as the only reference of truth ((Richmond, 2011).

Although it is rather new compared to previous generation of peace building, but the attention to the locality in the realm of local peace has attracted many social scientists to oversee. Research that began to pay attention to locality in the peace building process was carried out by Dorota Piotrowska (2015) in her thesis entitled "The Value of Culture in Peace building: Examples from Democratic Republic of Congo, Yemen dan Nepal". By using a bottom-up approach to build a local peace, she highlighted how local cultural values can be an important element of peace.

Ismene Gizels and Jonathan Joseph (2016) also given attention to the problem of locality in the term of peace building. They highlighted the lack of both women based civil society organizations and communities at the grassroots in the peace-building process in Liberia. According to the two researchers, the lack of women's involvement in the peace process is caused by decoupling or the distance between what was regarded as the international agenda and the value and capacity of the local sector. Both studies had the same orientation by giving attention to locality and in the same time being critical of globalization that was too dominant in the practice of liberal peace building.

Unfortunately, in the term of local peace, it is seldom that researchers sociologically explained it. The two studies above are two of the many studies that more represent the dominant image of peace building in non-sociological discipline such as the conflict and peace study and international relations. While how sociology explains the agency of local actors in developing peace based on local norms and values is lack of attention.

Whether local actors act independently of the influence of the social structure or they act just they were limited by the social structure in formulating peace, is the matter of the actor and social structure relations that can only be sociologically explained

The study of Mac Ginty (2014) entitled Everyday Peace; Bottom up and Local Agency in Conflict Affected Societies was a bit of study on local peace that uses sociological point of view. Ginty given more attention to the concept of agency and daily life world as a key aspect of peacebuilding.

Unfortunately we cannot put high expectation that this research can provide an adequate explanation of the sociologically concept of local peace. Ginty didn't fully stood on the conceptual and theoretical rank of the sociology. In his study, Ginty used interdisciplinary perspective, which was not only sociology such as international relations, social psychology, and anthropology. Moreover, according to Ginty "the 
exploration of the notion of everyday peace thus fits within the critical peace and conflict studies research agenda. The article also touches on a range of other debates in sociology, anthropology and political geography" (Ginty, 2014:552)

To fill the gap, by using Anthony Giddens' structuration theory I try to give a theoretical alternative to explain agent empowerment when faced social structures in the locality, while respecting the existence of structure as an important factor in influencing the existence of social agents in realizing social harmony.

\section{Research Method}

This research is a literature study which aimed at analyzing the concept of local peace by using structuration theory. Giddens' work became the main reference in this study. Some literatures those examine peace formation was also presented as the object of study analyzed through Giddens structuration.

This study relies on secondary data taken from several of the works mentioned above. By using the secondary data, i expect to dialectically conceptualize the circumstance of peace formation with the sociological theory of Giddens especially with reference to his central idea of structuration.

Using structuration, i sociologically explained two things related to the theme of peace formation. First, structuration explain the position of local actors in relation to local social structures; whether as member of society they were constrained such as in structural functionalism or they were fully dominant toward social structure such as in interpretive sociology. Second, the concept of actor awareness as a social agent can explain how the process of peace formation takes place around society.

The study ends in two findings. The first is that the relationship between actors and local social structures was dialectical; social actors as agents are consciously able to form peace based on structures that were socially owned while rejecting certain parts of them that were considered irrelevant to the practice of maintaining peace. In addition, with its position as a conscious and critical agent, the peace formation runs through the practices of significance, domination and legitimacy.

\section{Finding and Argument}

\section{A. Peace Formation and Locality}

The peace formation was a peace strategy that makes the social dynamics of local culture as a starting point. Richmond defined peace formation as "Relationships and networked processes where indigenous local agents of peace building, conflict resolution, development, or in customary, religious, cultural, social, or local political or local government settings find ways of establishing peace processes and sustainable dynamics of peace" (Richmond, 2013: 276).

Richmond's concept of local peace occurred as a critique of the tendency of liberal peace which was lack of the involvement of local actors as well as the lack of local values formed as the basis for such a peace building. Peace analysis was often 
seen as just based on state and international level point of view while ignoring the locality.

The concept of local was important part of peace formation. Richmond was doubtless the leading person in offering peace formation. That concept was coincidentally popular with the rise of locality while being critical of the global approach that marginalized locality.

Gary Alan Fine crystallized the symptoms of the rise of locality in the field of sociology by offering the concept 'sociology of the local'. Fine criticized the tendency of sociology which tend to abandon locality as the milestone of the emergence of global sociological theories. "For myself, I always write about Dublin, because if I can get to the heart of Dublin, I can get to the heart of all cities of the world. In the particular is contained the universal" is James Joyce's quotation that inspired Fine in building the sociology of local.

The sociology local, according to Fine, was the view "that particular circumstances provide opportunity structures that allow for developing meanings and structures and that these meanings and structures reverberate beyond group boundaries" (Fine, 2010:356). The word local here presupposes the tension between universalism and particularism or, as Fine uses, globalism and localism.

Post liberalism could be seen as the momentum of the rise of locality. Globallocal or international-local binary opposition made the melting of these two trends considered difficult to be. Richmond itself by emphasizing on locality didn't mean to ignore the global. In a metaphorical way, Richmond called the excessive resistance to what came from non-locality as part of local romanticization (Richmond, 2011: 26).

Therefore, the idea of peace formation didn't want to preserve local-global clashes, although Richmond's criticism of the global-liberal peace was very explicit. Richmond used the word local as "It represents fragmented, often disguised, and localized agencies and capacities, in a polity beyond the liberally projected artifice of elites and civil society (which are also driven by internal competition for funding and influence" (Richmond, 2013: 271).

\section{B. Structuration: Structure-Subject Duality}

The history of sociological debate can't be separated from the two extreme dimensions between the nature of structure-subject relationship; it was whether social structure constrained subject or subject stood independently from social structure. Giddens called the first preference as the theory of objectivism, while the subjectivism for the second one.

Giddens to explain objectivism as a third form of ism - along with naturalism and functionalism - which marked the orthodox consensus. They united over the common belief that, by marking Parson, "there is no doubt that in his theoretical scheme the object (society) predominates over the subject (the knowledgeable human agent)" (Giddens, 1984: xx). The weakness in objectivism was criticized by interpretive sociological thinkers proposed the theory of subjectivism; the subject controlled society as an object. Giddens called the emergence of these two extreme tendencies 'dualism'. 
Giddens' theory of structuration tried to resolve the chronic debate by offering a view that emphasized the duality of structure and subject. With the word structure, Giddens referred to 'structural property' or 'property structuring'. These properties referred to what Giddens mentioned explicitly as rules and resources (Giddens, 1979: $64)$.

If dualism viewed structure and subject as two elements which were always in tension, duality put both in a dialectical relationship. “...the notions of actions and structure presuppose one another..." (Giddens, 1979:53)

Giddens criticized the both objectivism and subjectivism. Departing from criticism of the two binary opposition, Giddens proposed the theory of structuration. Structuration was Giddens' way to get out from the debate between objectivism and subjectivism.

Giddens offered the principle of duality, instead of dualism, which focused on the dialectical relationship between agency and structures. According to Giddens, the relationship between the both had to be understood in a duality where each element couldn't be separated from the other. No one dominated the other. Structure and agents were like two sides of the one coin (Craib, 1992).

As agents, social members are creative actors who are free from the constraint of social structure as a system. Social actors were not only as products of society, but also dialectic with society. Such a dialectic offered understanding that social members were not able to completely break away from social structures.

Social actor acted based on existing social structures, which in the same time also needed social action from the actor to maintain continuity through the process of repetition of action. Therefore, each structure and agent was not a completely independent phenomenon, but dependently needed each other. Social structure, Giddens said, was just not the result, but also a medium of social action. "Structure is not to be equated with constraint but is always both constraining and enabling" (Giddens, 1984:25).

According to structuration theory individual was a purposive agent that always had a goal in every action he or she performed in the presence of structures (Giddens, 2003). Giddens used intentional and purposive words in the same meaning. According to Giddens, a purposive or intentional action was "any act which the agent knows (believes) can be expected to manifest a particular quality or outcome, and in which this knowledge is made use of by the actor in order to produce this quality or outcome" (Giddens, 1993:83)

Although to a certain degree he or she was not always aware, but as agent, each person knew what they were doing. Just like someone who came to a mosque to worship, he knew what he was doing, even though he was not fully aware of the actual motives of what he was doing; he might step into the mosque to worship, but it didn't mean he realized what the real purpose of worship is, for example to uphold religious morality 
Giddens divided consciousness into two kinds, namely discursive awareness and practical awareness. Plus one part of unconscious motives. These three ideas emerged from the Giddens critical of Sigmund Frued's psychological scheme of id, ego and super ego. However, Giddens didn't mean these three terminologies of consciousness parallel to the three Frued schemes above (Giddens, 1984).

\section{Unconscious Motive}

According to Ian Craib, Giddens describes motivation as one of the levels of action unconsciousness (1992). As we know, agent was actor who had purpose. However, there were actions taken without being based on an awareness of the reasons and objectives of the actions. This action was driven by a motivation, but not by conscious goals.

Giddens give a portion to explain the difference between purpose, reason, and motive. According to Giddens, the three terms were used interchangeable in everyday communication. Purposive conduct based on knowlodge that by doing so people can produce outcome. Therefore, purposive conduct is "knowledge which is applied" (Giddens, 1993:88).

Purposive action was commonly reproduced in everyday life because tha fact that it ends in an outcome which is similar to what people expect. By the relexive skill owned, the community continue to repeat these actions and accept them voluntarily. Reflexive monitoring is the strength that each actor has to evaluate what they do in their daily lives and allow them to comfortably maintain it recursively.

Meanwhile, reason has a more subtle understanding toward purpose. Giddens used the term 'rationalization of actions' in relation to agent's reflexive monitoring of action. Reflexive monitoring of action was related to the agent's ability to make criticisms and changes to certain social structures which he deems irrelevant. This reflexive ability shows the role of agent who were not constrained in relation to social structures, but enabled (Giddens, 1986: 67).

Giddens defined reason as "grounded principles of action which agent keep in touch with as a routine element of their reflexive monitoring of their behaviour" (Giddens, 1993:90). To simplify understanding over the differences between purpose and reason, Giddens referred to the illustration of Alfred Schutz. Schutz exemplified someone who uses an umbrella when it rains as an action the intention is keeping dry (purposive action). And the reason for doing that action is awareness that a certain suitable object which is held above the head can protect him or her of the rain (rationalization of action).

And the final term is motive. Giddens explain motive as 'wants' which prompt people to act. By the term, people often used various names as well as fear, vanity and the others. And in everyday usage, people uses the term to show the kinds of emotions. It is obvious then, why Giddens put the the motive of action in the level of unconsciousness. 


\section{Practical Consciousness}

Giddens paid great attention to the type of practical consciousness. According to Giddens, most people actually act on the basis of practical rather than discursive consciousness. According to Giddens, what people know about what they do and why they do it- their knowledgeability as agent- was largely carried by practical consciousness.

Giddens defined practical consciousness as all of things people know need to be conducted in the context of social life without being able to give argumentation discursively toward what and why they do it (Giddens, 1986). This concept of consciousness derived from the ethnomethodology and phenomenology. It is the level of consciousness that commonly people have in everyday life interaction.

People realize what they do although they are not always being able to explain it explicitly. They act based on what commonly people act practically and therefore, "we are conscious of these things in a practical, taken for granted way, we routinely rationalize what we do" (Craib, 1992: 25).

\section{E. Discursive Consciousness}

Discursive awareness is related to the level of consciousness of person acting by being based on the knowledge over the outcome he wants to manifest. Discursive consciousness was characterized by one's ability to give discursive arguments about what they do and why they do it (Giddens, 1986). It is seldom people to act based on this consciousness although we can guess Giddens put this term on the level of expectation, that people as an agent shoud act according to this consciousness.

\section{F. $\quad$ Three Central Structures}

Giddens theory of structuration consist partly of three central structures. They are signification, domination and legitimation. The three concepts occurred from the action itself (Craib, 1992). Giddens explain them in the term of his central concept of duality. To understand what he want by duality, we must refer to Giddens concept of modality. The modality is the mediation of interaction and structures. He used the three lines scheme to explain the operationalization of that modality; signification, domination and legitimation.

Signification is the phase where people produced action and then it enabled them to act again and communicate in everyday social life. Signification can be analyzed as systems of semantic rules or convention. For the first step, people in the signification phase, built communication in their interaction each other based on their shared value and knowledge. The cognitive aspect guided them how to communicate in the proper language and act according to the proper action. In their communication, people was not merely constrained by the action pattern, even they used interpretative schema by which they can reconstitute their action. This process enabled people to keep the interaction recursively.

Domination is the second stage of duality of structure. By this term, Giddens referred to what he called system of resources. It means the phase where participant in the interaction used the power to affect the conduct of others. Giddens explained the 
process of the use of the power in the way that participant of social life used facility recognized as power through the order of domination. The facility simultaneously, beside it was produced the order of domination, reproduce the order of domination (Giddens, 1979).

On the final stage, participant applied social norms through the practice of legitimation. According to Giddens, legitimation is the system of moral rules. The norms are drawn from the legitimate order and recursively reconstitute it more. To understand how the three structure operated around social life, take the practice of everyday life as example.

To call someone who transfers knowledge as teacher, as well as to call the Islamic teacher as ustad, is the practice of signification. To vote in the general election is the practice of domination, while respect one another as the religious obligation is the practice of legitimation.

\begin{tabular}{|c|c|c|c|}
\hline INTERACTION & Communication & Power & Morality \\
\hline (MODALITY) & Interpretative scheme & Facility & Norm \\
\hline TRUCTURE & Signification & Domination & Legitimation \\
\hline
\end{tabular}

Fig. 1. The schema of three central structures of Giddens (Cited from Giddens, 1993:129)

\section{G. Individual as a Peace Agent}

Peace formation involved the initiation of local actors as agents who are consciously able to form peace based on social structures they had while rejecting certain parts of them considered irrelevant to the practice of peace formation. Local peace made the local resources as the main ingredient. The local resources included local actors as agents themselves, as well as local norms. Local norm was part of the rules that Giddens understood as structure.

As purposive agent, local actors' action to initiate peace was not merely driven by the norm; with the duality of existing structures, the existing norms actually allow them to carry out reflexive monitoring over the parts of the norm that can be maintained in peace building.

Thus, the actor's relationship as an agent with the norm, was not dualistic; the actor was not merely subject to the norm in formulating peace, but the actor also consciously and critically accepted and eliminated elements of local norms that were not needed.

Local actors in their status as agents, act in constructive efforts towards peace, not mechanical. As agents, local actors acted based on one goal, whether or not they were aware, to create a peaceful situation around society. There were those who were able to explain discursively over the purpose to maintain a particular culture, or to ignore certain culture, through daily recursive practices. This category might not much, limited to local actors who had deep consciousness with the ability to capture contextual messages of culture. 
Most of the local actors acted based on practical consciousness in creating harmony and peace. They acted according to one culture recorded in their world of everyday life by which social harmony was truly formed. Therefore, norms or cultures that play a role in maintaining social order appeared to be taken for granted.

To explain how agents form peace from locality, we must refer to the concept of three structures of Giddens' modality namely signification, domination and legitimation. At the stage of signification, the community marked on several cultural emblems that they maintained as a bastion of social integration in their life. For example, how halal bi halal was characterized as a means of cultural communication that served to maintain harmony by forgiving and forgetting mistakes. Halal bihalal participants were sometimes made inclusive; those from different religions also blended in.

The owners of political power also contribute to making local culture an effective means for peace building such as to guarantee mutual respect for the rights and obligations between religious communities. Some regulations were made by the government to ensure that, in the month of Ramadan, each party respected the rights of Muslims who fasted.

The government could use the power facilities it had to prohibit anyone from disturbing the solemnity of those who fasted. The involvement of the government as the state authority to influence people to respect one another was the practice of domination. While affirming normative rules as a means to enable certain practices of peace to be carried out and maintained was the practice of legitimacy. Through legitimacy, maintaining order and peace was given a normative basis in which everyone must submit to.

\section{Conclusion}

This study presents a sociological analysis of the concept of peace formation. Based on sociological analysis using Giddens structure, this study culminates in two main conclusions. First, local actors as agents acted consciously to initiate peaceful life by making local norms one of the main ingredients. As agents, local norms do not merely move and force actors to act mechanically without the ability to evaluate them. Local actors actually dialectic with the norm structure; Reflexive monitoring capabilities allow them to reproduce norm-based actions or may produce new actions that are different from the norm's demands.

In its position as an agent, the action to follow norms that were compatible with the peace agenda, or reject counterproductive norms peacefully, is carried out with the knowledge that one action is useful or not to create peace. Although they knew, there were those who were not aware of the purpose of certain actions toward social order. Some others act not merely conscious but are also able to explain with a clear narrative the purpose of certain actions for peace (discursive awareness). While following Giddens, most people may not be able to explain discursively the purpose of their 
action, but in their daily lives they accepted that certain actions need to be done in order to form a peace (practical awareness).

Second, the agency of local actors in the formation of peace can be explained through the three structures of the Giddens modality. All three, namely signification, domination and legitimation provide a sociological explanation of how local actors were involved in the creation of peace at the local level by making local norm or culture as basic infrastructure

\section{Acknowledgment}

I expresses my gratitude to the parties who have provided support to me in various roles, such as providing references, inserting time to discuss, and giving moral injections to finish this study. I would like to thank the honorable reviewers for their criticism and suggestions. As well as for the ISSRD committee who have received this paper to be presented and published in the intended activity. Finally, thanks to all my family whose existence has always been a motivation for me to complete this study.

\section{References}

Craib, I. (1992). Anthony Giddens. London: Routledge.

Fine, G.A. (2010). The Sociology of the local: action and its publics. Sociological Theory, 28: 355

Giddens, A. (1979). Central problem in social theory: action, structure and contradiction in social analysis. London: Macmillan Education.

Giddens, A. (1984). The Constitution of society: outline of the theory of structuration. Cambridge: Polity Press.

Giddens, A. (1993). New rules of sociological method: a positive critique of interpretive sociologies. Cambridge: Polity Press.

Ginty, R.M. (2014). Everyday peace: Bottom-up and local agency in conflict-affected societies. Security Dialogue, 45(6) 548-564.

Gizelis, I \& Joseph, J. (2016). Decoupling local ownership? The lost opportunities for grassroots women's involvement in Liberian peace building. Cooperation and Conflict, 51(4), 539-556.

Piotrowska, D. (2015). The Value of Culture in Peace building: Examples from Democratic Republic of Congo, Yemen and Nepal. Master's Theses, City College of New York

Richmond, O.P (2013). Peace formation and local infrastructures for peace. Alternatives: Global, Local, Political, 38, 271-287

Richmond,O. P. (2011). Post liberal peace. London: Routledge. 